\title{
The Effects of Hot Corrosion Pits on the Fatigue Resistance of a Disk Superalloy
}

\author{
Timothy P. Gabb, Jack Telesman, Brian Hazel, and David P. Mourer
}

\author{
(Submitted February 5, 2009)
}

\begin{abstract}
The effects of hot corrosion pits on low-cycle fatigue life and failure modes of the disk superalloy ME3 were investigated. Low-cycle fatigue specimens were subjected to hot corrosion exposures producing pits, then tested at low and high temperatures. Fatigue lives and failure initiation points were compared to those of specimens without corrosion pits. Several tests were interrupted to estimate the fraction of fatigue life that fatigue cracks initiated at pits. Corrosion pits significantly reduced fatigue life by 60 to $98 \%$. Fatigue cracks initiated at a very small fraction of life for high-temperature tests, but initiated at higher fractions in tests at low temperature. Critical pit sizes required to promote fatigue cracking were estimated based on measurements of pits initiating cracks on fracture surfaces.
\end{abstract}

Keywords aerospace, corrosion testing, failure analysis, mechanical testing, superalloys

\section{Introduction}

Increasing turbine inlet temperatures allow improved turbine engine efficiency, which can decrease fuel consumption and increase performance in aerospace propulsion applications. However, this results in higher disk rim temperatures in some projections (Ref 1). As disk rim temperatures approach $700{ }^{\circ} \mathrm{C}$, salt contaminants from intake air, engine components, and combustion could melt. The liquid salt mixture could then attack such disk surfaces. Type II hot corrosion mechanisms, in which the protective oxide formed on superalloys is locally reduced by the salt and rendered nonprotective (Ref 2 ), could then form hot corrosion pits.

Much of the published hot corrosion and associated oxidation studies of gas turbine engine materials have focused on turbine blade, vane, and combustor materials at high temperatures of 800 to $1000{ }^{\circ} \mathrm{C}(\operatorname{Ref} 3,4)$. These components are often limited by high-temperature creep or thermal fatigue, due to these high temperatures. However, material consumption and pits produced by hot corrosion attack can reduce their expected life. Turbine rotor disks, interstage rings, and seals have been designed for high strength, fatigue, creep, and oxidation resistance at lower temperatures up to $700{ }^{\circ} \mathrm{C}$. The "disk" superalloys employed here are often limited by fatigue due to the very high centrifugal forces exerted by rotation of these parts, attendant turbine blades, and other attached hardware. Relatively few studies have been published on the

Timothy P. Gabb and Jack Telesman, NASA Glenn Research Center, 21000 Brookpark Rd., Cleveland, OH 44135; Brian Hazel, GE Aviation, 1 Neumann Way, Cincinnati, OH 45215; and David P. Mourer, GE Aviation, 1000 Western Ave., Lynn, MA 01910. Contact e-mail: tim.gabb@grc.nasa.gov. effects of hot corrosion pitting damage on disk superalloy durability. However, pits produced by a plating process were definitively shown to initiate fatigue cracks and limit fatigue life of a cast and wrought disk superalloy Inconel 718 (Ref 5). More recent work (Ref 6) has shown that pits produced by hot corrosion can form on a newer, powder metallurgy disk superalloy RR1000, potentially lowering fatigue life.

The effects of corrosion pits on fatigue life have been studied closely in various other alloys (Ref 7-9). In this work, fatigue crack initiation at pits has often been considered to occur very early in fatigue life. Fatigue life modeling of pitted materials has therefore often been concentrated on fatigue crack growth, using initial crack dimensions of the pit cross section. However, such assumptions would need to be verified before application to pitted superalloy disks.

The objective of this study was to determine effects of hot corrosion on low-cycle fatigue life and failure modes of ME3 disk superalloy. Low-cycle fatigue specimens were machined from several disks, subjected to hot corrosion exposures, and then tested at low and high temperatures. Fatigue lives and failure initiation points were compared to those of specimens without corrosion exposures. Several tests were interrupted to estimate the fractions of fatigue life at which fatigue cracks initiate at pits.

\section{Material and Procedures}

A recently developed powder metallurgy disk superalloy ME3, also sometimes referred to as Rene 104 and ME16 (Ref 10-12), was argon atomized, consolidated, hot compacted, extruded, and isothermally forged into disks approximately $61 \mathrm{~cm}$ diameter with a $5 \mathrm{~cm}$ maximum thickness. The disks were then supersolvus solution heat treated, and given aging heat treatments (Ref 13). Cylindrical low-cycle fatigue specimens were machined having a gage diameter of $10.2 \mathrm{~mm}$ and gage length of $19 \mathrm{~mm}$ with a low-stress ground and polished finish. A subset of specimens was shot peened. A mixture of sulfur-containing salts was then applied to the middle of the 
gage sections for a group of these specimens. They were then exposed in air at $704{ }^{\circ} \mathrm{C}$ for 8 and $24 \mathrm{~h}$ within a resistance heating furnace to produce accelerated hot corrosion damage. This corrosion treatment was not intended to exactly reproduce the make-up of contaminants from a particular instance of engine service or to simulate actual temperature-time conditions for a turbine disk location. Instead, the treatment was intended to rapidly produce hot corrosion attack in the form of pits to assess the potential effects of pits on fatigue life.

Low-cycle fatigue tests were performed in a servo-hydraulic test system with specimen heating by a direct induction system and specimen strain measured by an axial extensometer. Tests were initiated with strain controlled using a triangular waveform at a frequency of $0.33 \mathrm{~Hz}$. These tests were performed at $204{ }^{\circ} \mathrm{C}$ with a strain range of $0.5 \%$, and at $704{ }^{\circ} \mathrm{C}$ with a strain range of $0.75 \%$. The ratio of minimum over maximum strain (R) was maintained at 0 for both cases. Tests surviving beyond $24 \mathrm{~h}$ were interrupted, and then continued to failure with load controlled using a triangular waveform at a frequency of $5 \mathrm{~Hz}$. The load levels here were adjusted for each test to maintain the same maximum and minimum stresses as immediately prior to test interruption. All tests were run to failure, although several tests were periodically interrupted before failure to determine when the onset of surface fatigue crack initiations occurred in tests. Five tests were performed at each temperature for each condition to estimate mean fatigue life: as-machined with a low-stress ground finish (LSG), low-stress ground and subsequently shot-peened (SP), LSG then corroded $8 \mathrm{~h}(\mathrm{LSG}+8 \mathrm{~h})$, LSG then corroded $24 \mathrm{~h}(\mathrm{LSG}+24 \mathrm{~h})$, SP then corroded $8 \mathrm{~h}$ $(\mathrm{SP}+8 \mathrm{~h})$, and SP then corroded $24 \mathrm{~h}(\mathrm{SP}+24 \mathrm{~h})$. Fractography was performed to quantify failure initiation sites on all specimens using a JEOL 6100 scanning electron microscope (SEM). Several longitudinal sections of failed specimens were metallographically prepared and examined using optical and scanning electron microscopes and a JEOL JXA-8200 scanning electron microprobe.

The depth, width, and cross-sectional area of each pit initiating a fatigue crack on the fracture surface of each specimen were determined and compared. Subsequently, these dimensions were grouped by test condition and ranked to estimate cumulative probability of fatigue cracking versus pit depth, width, and cross-sectional area. Cumulative probabilities of crack occurrence versus pit dimensions were assessed using SuperSMITH(R) Weibull software of Fulton Findings, LLC. Two different statistical distribution assumptions were evaluated and fit by rank regression: log normal and 3-parameter Weibull distributions. In the log normal distribution, the natural logarithm of each dimension $(x)$ was regressed to estimate a mean value $(\mu)$ and standard deviation $(\sigma)$, then employed in the following cumulative distribution function:

$\mathrm{CDF}_{\ln }=1 / 2+1 / 2 \operatorname{erf}[(\ln (x)-\mu) /(\sigma \sqrt{ } 2)]$

In the 3-parameter Weibull distribution (Ref 14), the data was regressed to determine a Weibull slope $(\beta)$, characteristic value $(\eta)$, and offset $\left(t_{\mathrm{o}}\right)$ that was used in the cumulative distribution function:

$\mathrm{CDF}_{\text {Weib3 }}=1-\exp \left[-\left(\left(x-t_{\mathrm{o}}\right) / \eta\right)^{\beta}\right]$

Note that a fitted Weibull distribution can approximate other distribution functions, including the normal, exponential, Rayleigh, and some Poisson and Binomial distributions (Ref 15). Goodness of fit was assessed using the coefficient of determination adjusted for the number of estimated parameters, $R_{\text {adj }}^{2}$, where a value of 0.50 indicates $50 \%$ of the response variation is attributable to the variables and a value of 1.0 indicates $100 \%$ of the response variation is attributable to the variables. Other statistics generated in the SuperSMITH software were also sometimes used to further assess fit.

For estimation of residual stress and cold work in the shotpeened specimens before and after corrosion exposures, the gage section of one untested, shot-peened fatigue specimen was sliced transversely to produce several cylindrical gage segments. One segment was retained in this state, while other segments were exposed in a resistance heating furnace at $704{ }^{\circ} \mathrm{C}$ for 8 and $24 \mathrm{~h}$. Residual stress and cold work at the surface were subsequently measured by $\mathrm{x}$-ray diffraction in the loading direction at six points spaced $30^{\circ}$ apart circling around the segment perimeter. Residual stress and cold work were then determined as functions of depth at one of these locations on each segment by sequentially electropolishing material of known thickness and performing x-ray measurements. All surface measurements were then corrected for the near-surface stress gradient using the corresponding depth profile of the appropriate specimen. The x-ray measurements were performed at Lambda Technologies, Inc., Cincinnati, $\mathrm{OH}$ using the twoangle sine-squared-psi technique in accordance with SAE HS-784. Diffraction of $\mathrm{Mn} \mathrm{K} \alpha$ radiation by the (311) planes was performed to determine peak intensity, breadth, and angular position (Ref 16).

\section{Results and Discussion}

\subsection{Material}

Typical microstructures from the test material are shown in Fig. 1 (Ref 13). The material ranged in average grain size from 25 to $34 \mu \mathrm{m}$ and as-large-as grain size of 90 to $170 \mu \mathrm{m}$. Mean diameters for secondary $\gamma^{\prime}$ precipitate ranged from 0.19 to $0.33 \mu \mathrm{m}$ and for tertiary $\gamma^{\prime}$ precipitates ranged from 18 to $39 \mathrm{~nm}$. These differences in specimen microstructure were due to varying prior location of specimens from within disks which had been given intentionally varied solution quench heat treatments (Ref 13). Specimens for each test condition were selected from multiple disks and locations to span this range of microstructure and associated mechanical response.

Fatigue specimen surfaces after the hot corrosion exposures are shown in Fig. 2. The salt mixture, applied in a ring around the middle of the gage section, melted at $704{ }^{\circ} \mathrm{C}$ and caused pits to form within and along the edges of this ring. The $8 \mathrm{~h}$ corrosion exposure produced fewer, usually separated pits that were near hemispherical in profile, as indicated by the arrows. The $24 \mathrm{~h}$ exposure produced a higher density of pits, which were sometimes joined together along the ring edges, also indicated. The range of pit morphologies captured by 8 and $24 \mathrm{~h}$ exposures allowed determination of how variations in pit characteristics influence fatigue life.

Oxide layers were sometimes retained within and over pits, but in other cases the oxide layers spalled, to openly expose the pits. Open pits are shown at higher magnification in the SEM image of Fig. 3. The delineation of grain boundaries in the open pit of Fig. 3 indicates localized corrosion attack at the grain boundaries occurred within these pits. This was easily observed in some, though not all pits. 


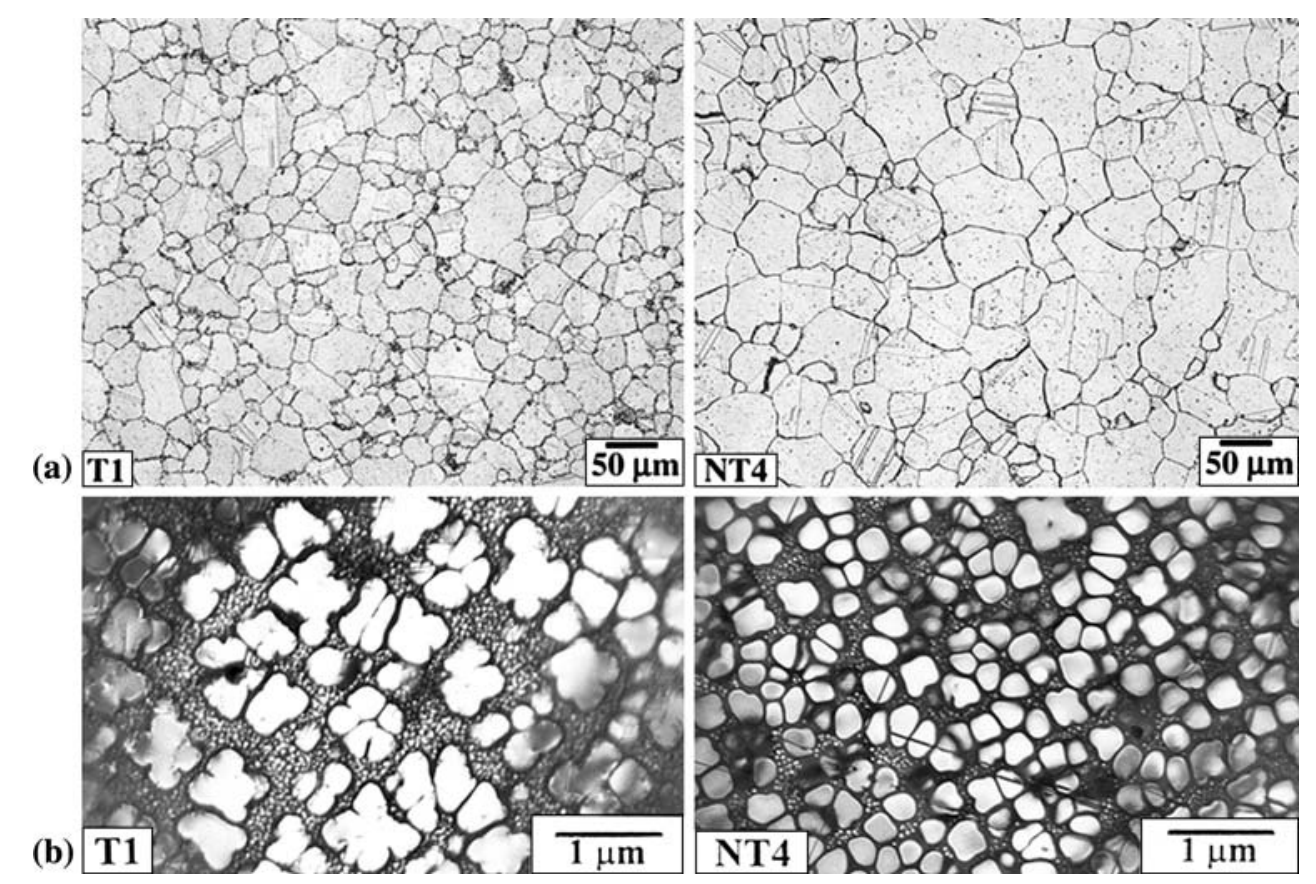

Fig. 1 ME3 disk bore (T1) and rim (NT4) microstructures: (a) Grain structure and (b) $\gamma^{\prime}$ precipitate structure

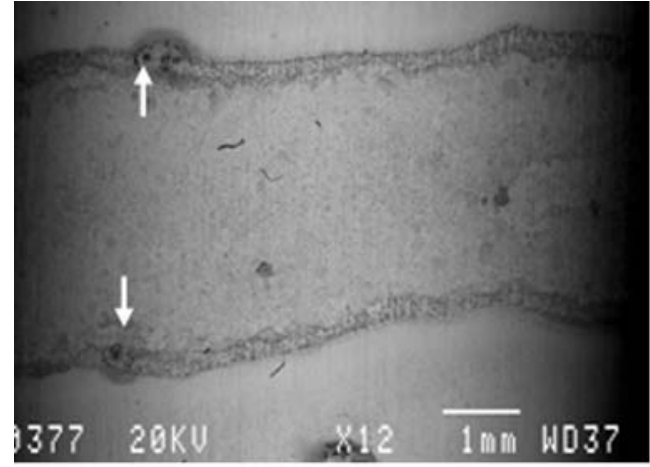

(a)

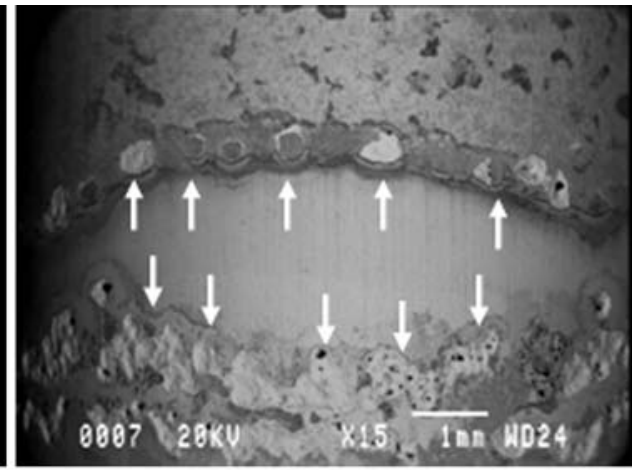

(b)

Fig. 2 Corroded fatigue specimens with the loading direction oriented vertically, arrows indicating corrosion pits: (a) $8 \mathrm{~h}$ exposure and (b) $24 \mathrm{~h}$ exposure

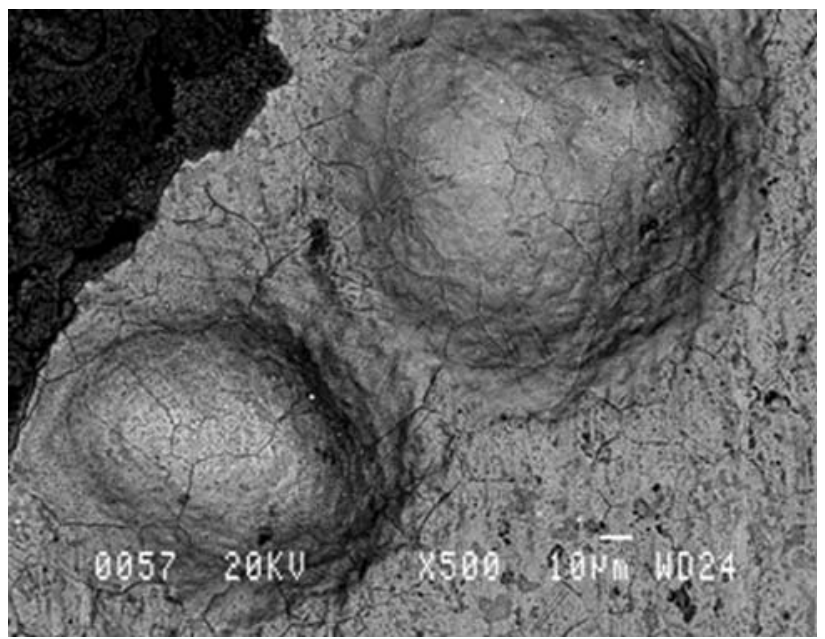

Fig. 3 Corrosion pits with evidence of intergranular attack
A cross section containing a pit with the oxide layers still attached is shown in Fig. 4 from a metallographically prepared section of a specimen. This pit section was analyzed using a scanning electron microprobe, and the major oxide layers in the pit are identified in the figure. Outer porous layers of nickel and cobalt oxide covered entrapped salt particles. Within these outer layers were very fine alternating layers of chromium, aluminum, titanium, and nickel oxides. CrS was present at the innermost layer of attack in the pit. This damage was consistent with a hot corrosion attack mechanism whereby the molten salt breaks down the chromium and aluminum oxides, rendering them nonprotective and allowing sulfur penetration and attack of the substrate to form $\mathrm{CrS}$ at the corrosion front (Ref 2).

\subsection{Fatigue Life Response}

The lives of low-cycle fatigue tests performed at 204 and $704{ }^{\circ} \mathrm{C}$ are tabulated in Table 1 and compared in Fig. 5. Evaluations indicated the logarithm of lives could be treated as 


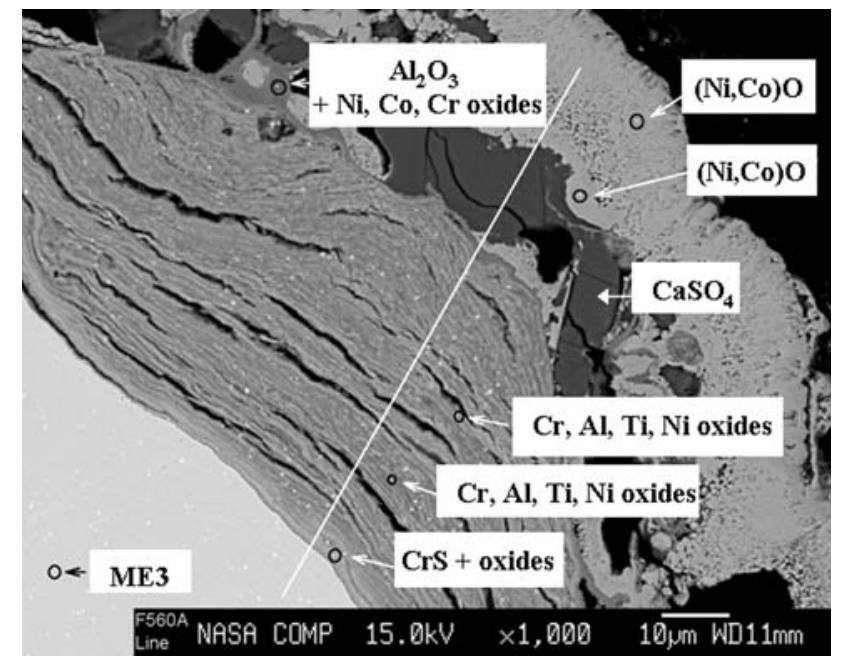

Fig. 4 Corrosion products identified by microprobe on pit cross section

Table 1 Specimen and fatigue test conditions with mean life results

\begin{tabular}{lccc}
\hline Machining condition & $\begin{array}{c}\text { Test } \\
\text { Corrosion } \\
\text { time, h }\end{array}$ & $\begin{array}{c}\text { Temperature, } \\
{ }^{\circ} \mathbf{C}\end{array}$ & $\begin{array}{c}\text { Log mean life, } \\
\text { cycles }\end{array}$ \\
\hline Low-stress ground & 0 & 204 & 147,924 \\
Low-stress ground & 8 & 204 & 57,175 \\
Low-stress ground & 24 & 204 & 34,616 \\
Shot peened & 0 & 204 & 254,527 \\
Shot peened & 8 & 204 & 250,908 \\
Shot peened & 24 & 204 & 75,921 \\
Low-stress ground & 0 & 704 & 80,099 \\
Low-stress ground & 8 & 704 & 3,768 \\
Low-stress ground & 24 & 704 & 1,970 \\
Shot peened & 0 & 704 & 92,936 \\
Shot peened & 8 & 704 & 13,202 \\
Shot peened & 24 & 704 & 3,616 \\
\hline
\end{tabular}

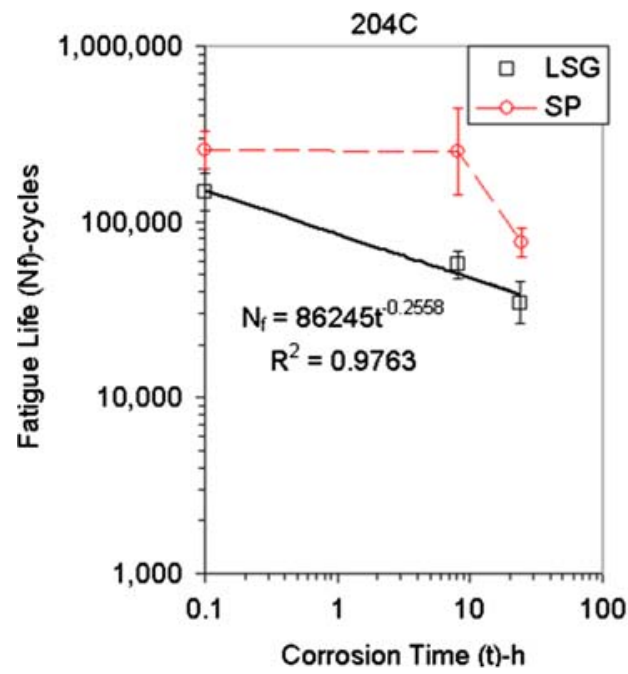

normally distributed, so mean lives were computed from the $\log ($ life) values and back transformed for comparisons versus corrosion time in Fig. 5. Hot corrosion substantially reduced mean fatigue life by between 60 and $98 \%$. The largest reductions were observed in tests at $704{ }^{\circ} \mathrm{C}$, where the $\mathrm{LSG}+24 \mathrm{~h}$ corroded condition reduced life from the LSG condition by $98 \%$. In tests at $204{ }^{\circ} \mathrm{C}$, this LSG $+24 \mathrm{~h}$ corroded condition reduced mean life by $77 \%$. Cyclic fatigue life $\left(N_{\mathrm{f}}\right)$ approximately varied with hot corrosion time $(t)$ according to a power law relationship for LSG specimens:

$N_{\text {f } 204{ }^{\circ} \mathrm{C}}=86,245 t^{-0.2558}$
$N_{\mathrm{f} 704{ }^{\circ} \mathrm{C}}=17,097 t^{-0.6941}$

Shot peening of specimens increased mean life for all conditions, but by varying degrees. The positive effect of shot peening was most pronounced for specimens tested at $204{ }^{\circ} \mathrm{C}$ after $8 \mathrm{~h}$ corrosion exposure. As shown in Fig. 5, whereas the mean fatigue life of the unpeened specimens tested at these conditions was reduced by over $50 \%$, the shot peened specimens given the same $8 \mathrm{~h}$ exposure showed equivalent mean life to the unexposed specimens. However, for the specimens given $24 \mathrm{~h}$ of corrosion exposure and tested at $204{ }^{\circ} \mathrm{C}$, shot peening was not able to compensate for the corrosion damage and accordingly the SP $+24 \mathrm{~h}$ fatigue life was considerably shorter than for the unexposed specimens. For tests at $704{ }^{\circ} \mathrm{C}$ after both corrosion times, shot peening did not negate the effects of subsequent hot corrosion on mean fatigue life. The power law relationship with corrosion time was less applicable here.

\subsection{Residual Stress Response}

The variation in benefits of shot peening on life could be due in part to the evolution of associated residual stress and cold work during corrosion treatments and fatigue testing. Therefore, axial residual stress and cold work were determined by $\mathrm{x}$-ray diffraction on sections from an untested shot-peened specimen given exposure times of 0,8 , and $24 \mathrm{~h}$ at $704{ }^{\circ} \mathrm{C}$. Mean residual stress and cold work at the surface are compared as functions of exposure in Fig. 6 and 7. Mean compressive residual stress (CRS) strongly decreased in magnitude with just

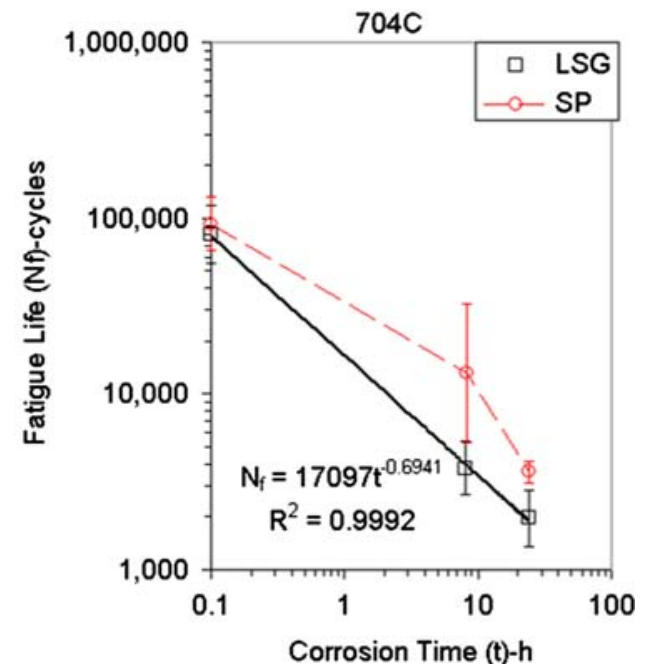

Fig. 5 Comparison of $\log$ mean fatigue lives and their $95 \%$ confidence intervals 

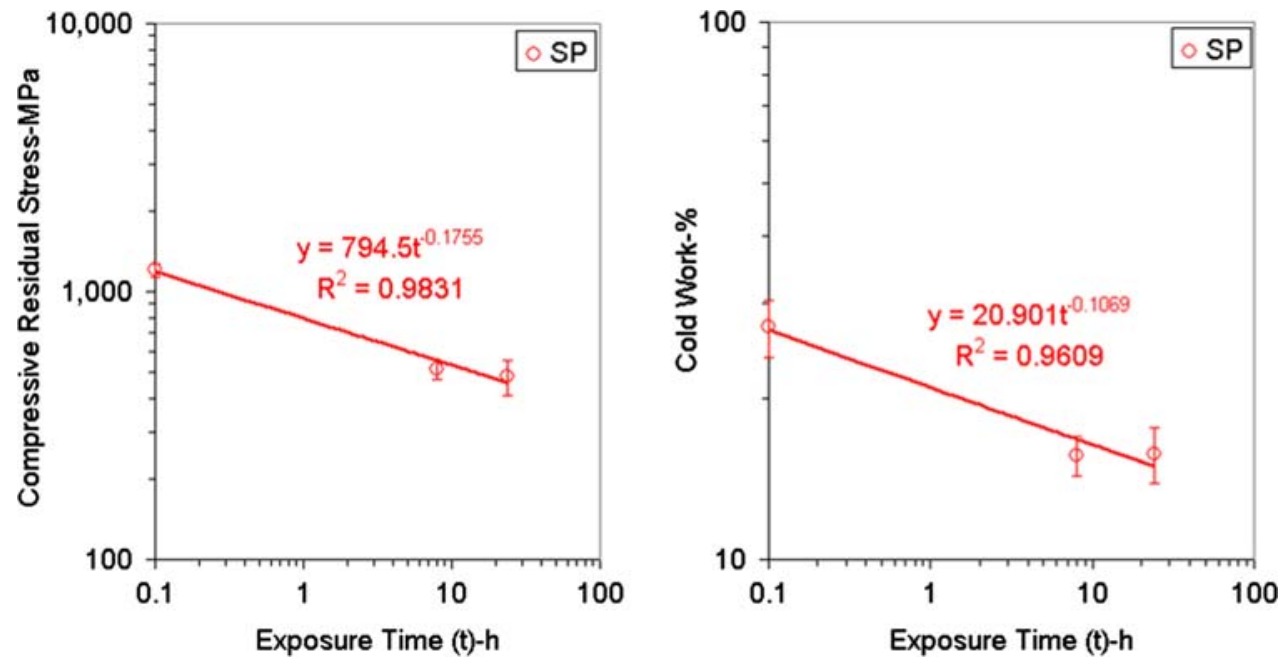

Fig. 6 Comparisons of mean surface residual stress and cold work for shot-peened fatigue specimen sections exposed at $704{ }^{\circ} \mathrm{C}$ with their $95 \%$ confidence intervals
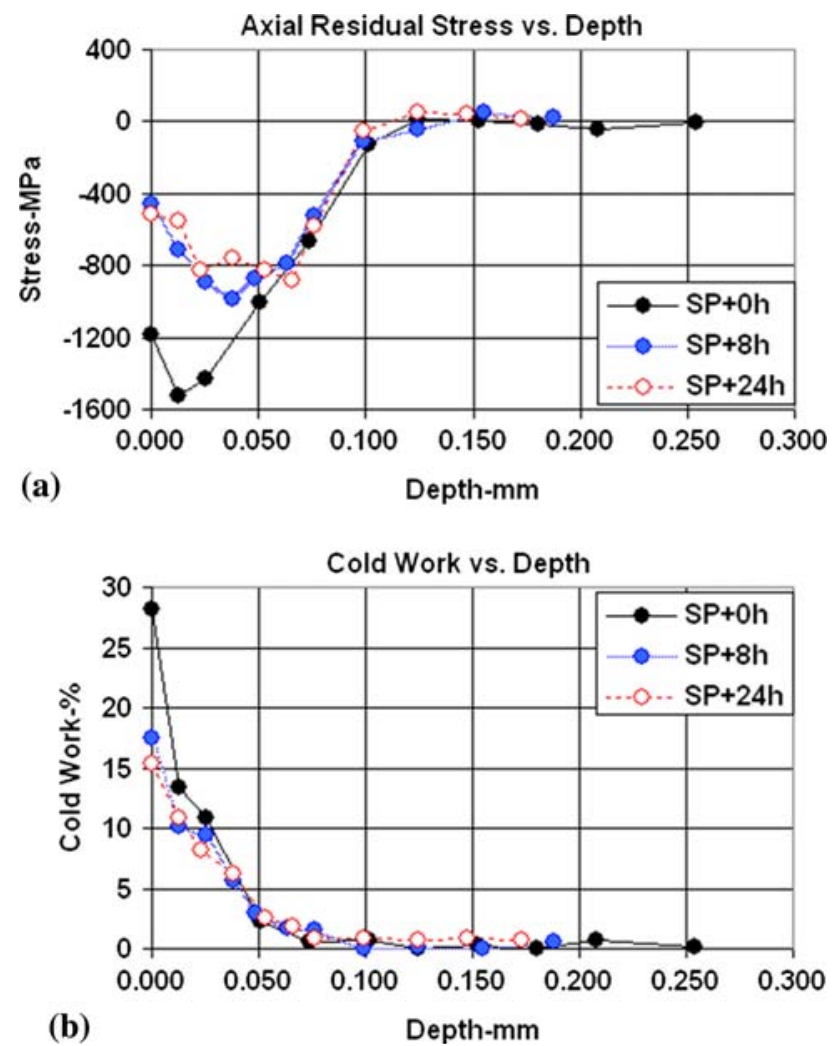

Fig. 7 Comparisons of shot-peened fatigue specimen sections exposed at $704{ }^{\circ} \mathrm{C}$ : (a) axial residual stress vs. depth and (b) cold work vs. depth

$8 \mathrm{~h}$ exposure at $704^{\circ} \mathrm{C}$, while further exposure to $24 \mathrm{~h}$ produced only a small additional decrease in residual stresses, according to the power law relationship shown below:

$\mathrm{CRS}=794.5 t^{-0.1755}$

Cold work magnitude similarly decreased with exposure time. Corresponding plots of residual stress and cold work versus depth are compared for the three conditions in Fig. 7.

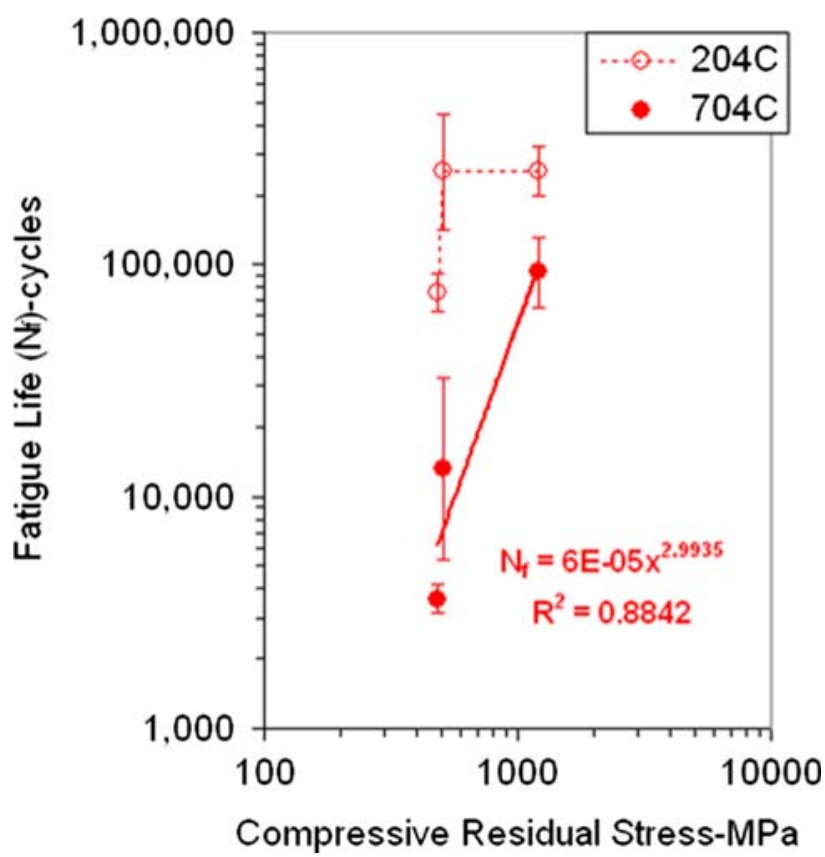

Fig. 8 Correlation of mean fatigue life with surface compressive residual stress for shot-peened fatigue specimens, where corroded specimens have reduced stresses

Maximum compressive residual stress occurred beneath the surface with the magnitude of the maximum compressive stress also decreased in magnitude with increasing exposure time. The depth of compressive residual stresses and cold work remained about $0.1 \mathrm{~mm}(100 \mu \mathrm{m})$.

Mean compressive residual stresses at the surface versus mean $\log$ (life) of shot-peened specimens are shown in Fig. 8. The reductions of beneficial compressive residual stress with exposure time were often associated with reductions in mean fatigue life of shot-peened specimens, but not consistently. A corrosion time of $8 \mathrm{~h}$ at $704{ }^{\circ} \mathrm{C}$ strongly reduced compressive residual stress by $57 \%$, where the accompanying mean fatigue life was reduced by $86 \%$. However, continuing exposure to 
$24 \mathrm{~h}$ further decreased the compressive residual stress by only $6 \%$, while further decreasing fatigue life by $73 \%$, a very significant reduction. This lack of consistent time dependence was even more evident in fatigue tests at $204{ }^{\circ} \mathrm{C}$, where mean life was unchanged after $8 \mathrm{~h}$ corrosion, but dropped after $24 \mathrm{~h}$ corrosion by $70 \%$.

The differences in residual stress-mean fatigue life relationships at the two test temperatures could be due in part to the influences of cyclic loading on these compressive residual stresses. Cyclic plastic flow during initial fatigue cycling at both test temperatures may reduce compressive residual stresses near the surface. Additional time-dependent relaxation of compressive residual stresses near the surface of shot-peened specimens could occur at the high $704{ }^{\circ} \mathrm{C}$ test temperature (Ref 12) with continued fatigue cycling at $704{ }^{\circ} \mathrm{C}$. These factors appeared to often reduce the ability of compressive surface residual stresses from shot peening to suppress crack initiations at the specimen's surface pits for improved life, as will be subsequently shown.

\subsection{Fatigue Failure Modes}

The failure initiation sites were identified for all specimens with typical results compared in Fig. 9. Failures for specimens not corroded occurred at relatively large grains, which failed on crystallographic planes. Such failures are often termed "facet" grain failures, and are commonly observed in ME3 (Ref 17). Some of these failures were at or near the specimen surfaces, while others were internal and away from the surface. Failures of most corroded specimens initiated from hot corrosion pits at the specimen surface. For specimens tested at $204{ }^{\circ} \mathrm{C}$, failures usually initiated at grain facets along the pits. In corroded specimens tested at $704{ }^{\circ} \mathrm{C}$, cracks initiated along grain boundaries connected to the pit surfaces. Multiple failure initiation sites were present for specimens corroded $24 \mathrm{~h}$, while fewer or even single failure initiation sites were present for specimens corroded $8 \mathrm{~h}$. These results consistently applied for all corroded specimens having large reductions in life from the baselines.

However, the failure mode shifted for most, though not all, $\mathrm{SP}+8 \mathrm{~h}$ corroded specimens tested at $204{ }^{\circ} \mathrm{C}$, which had no reduction in mean life. For this one case, cracks initiated at internal grain facets rather than at surface pits to cause failure in four out of five of the $\mathrm{SP}+8 \mathrm{~h}$ specimens giving no reductions in mean life. The remaining specimen had cracks initiated both from an internal grain facet and at two surface pits (Fig. 10) and lower resulting life. Thus, for the SP $+8 \mathrm{~h}$ condition with tests conducted at $204{ }^{\circ} \mathrm{C}$, compressive residual stresses produced by shot peening were apparently sufficient to mostly suppress fatigue cracking at surface pits, which greatly benefited fatigue life. Yet, in all other SP $+8,24 \mathrm{~h}$ test conditions, the compressive residual stresses were apparently reduced by plastic flow and time-dependent stress relaxation sufficiently to still allow fatigue cracking at the pits with large reductions in life.

Several fatigue tests were interrupted at cycling intervals to study the onset of crack initiation and assess the mechanisms of crack initiation and propagation at pits. Typical pits on the surfaces of LSG $+24 \mathrm{~h}$ specimens are shown for fatigue cycles at 204 and $704{ }^{\circ} \mathrm{C}$ in Fig. 11 with the load direction oriented vertically. Specimens tested at $204{ }^{\circ} \mathrm{C}$ did not have identifiable fatigue cracks within the pits when first interrupted at 250 cycles. However, specimens tested at $704{ }^{\circ} \mathrm{C}$ for only
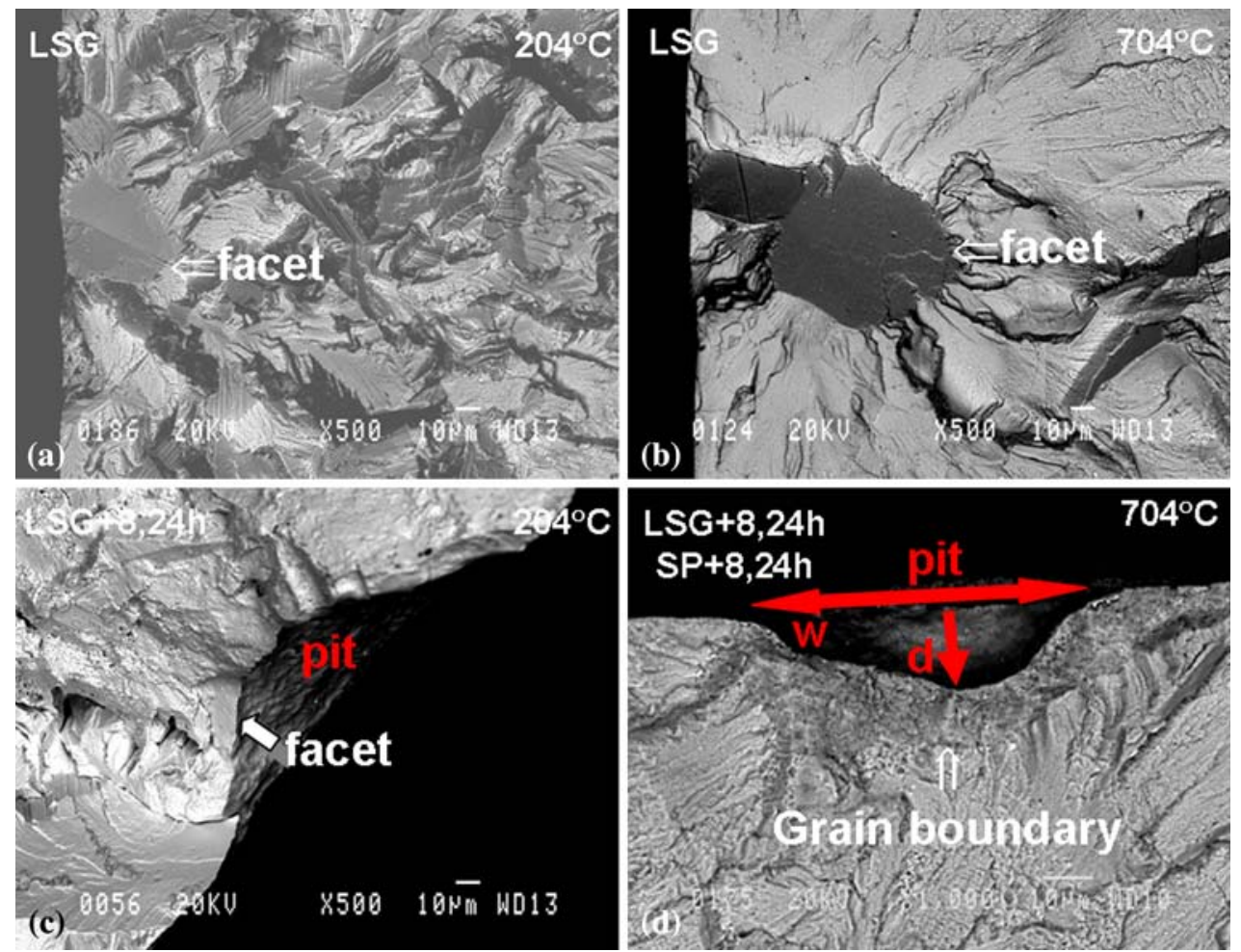

Fig. 9 Typical fatigue failure initiation points: (a) LSG at $204{ }^{\circ} \mathrm{C}$; (b) LSG at $704{ }^{\circ} \mathrm{C}$; (c) $\mathrm{LSG}+8,24 \mathrm{~h}$ at $204{ }^{\circ} \mathrm{C}$; and (d) $\mathrm{LSG}+8,24 \mathrm{~h}$ and $\mathrm{SP}+8,24$ h at $704{ }^{\circ} \mathrm{C}$ 

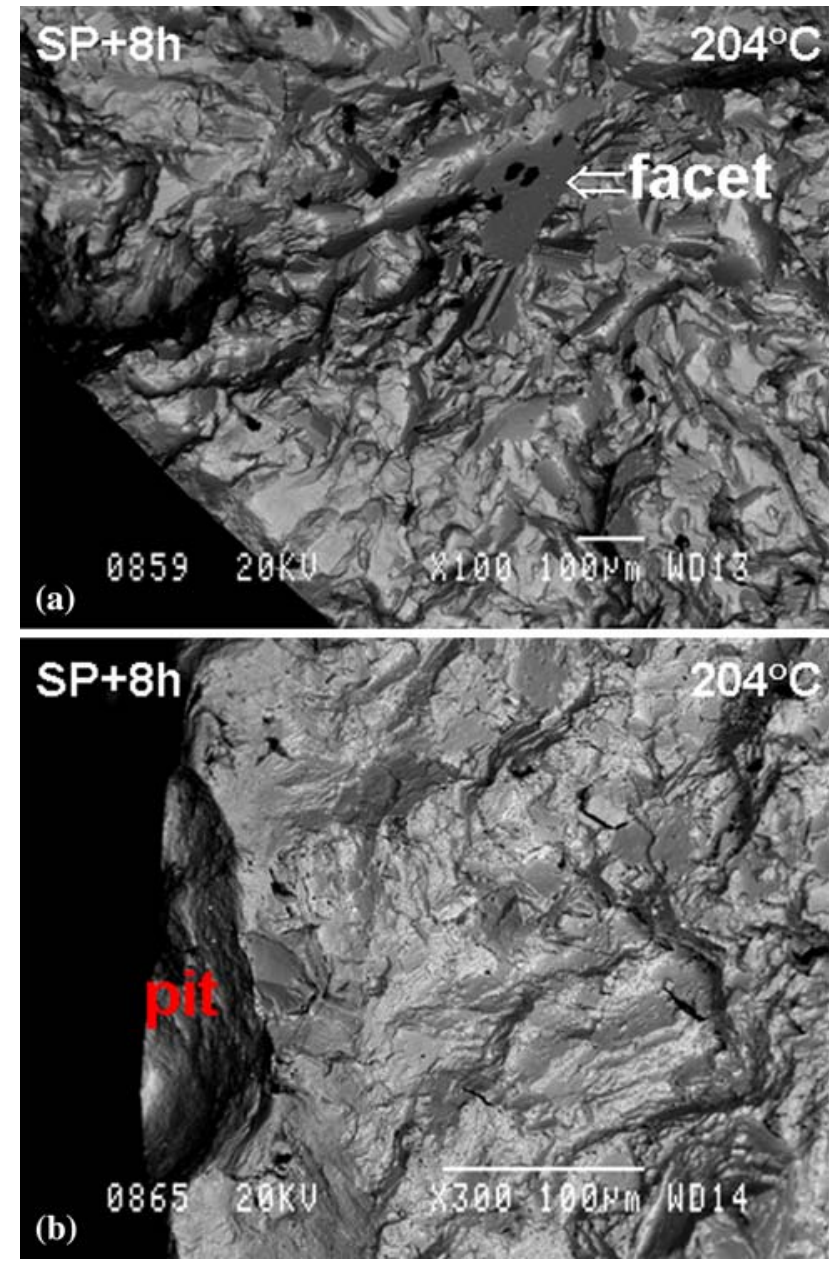

Fig. 10 Failure initiation points for $\mathrm{SP}+8 \mathrm{~h}$ specimen tested at $204{ }^{\circ} \mathrm{C}$ having lowest life for this condition of 122,917 cycles: (a) internal grain facet and (b) surface pit

250 cycles already had cracks present with the cracks initiated along grain boundaries nearly normal to the loading axis, Fig. 11(b). Multiple cracks initiated along the grain boundaries within the corrosion pits very early in tests at $704{ }^{\circ} \mathrm{C}$, which coalesced and grew for the remaining large majority of life to cause failure. In the case of tests at $204{ }^{\circ} \mathrm{C}$, the first cracks were not detected until approximately $1 / 3$ to $1 / 2$ of life was consumed for each corroded condition, e.g., at least 10,000 cycles for the LSG $+24 \mathrm{~h}$ case. In contrast to the $704{ }^{\circ} \mathrm{C}$ tests, the crack initiation within the corrosion pits at $204{ }^{\circ} \mathrm{C}$ was transgranular with the cracks appearing on apparent crystallographic facets as shown in Fig. 11(a). This indicated a substantial portion of fatigue life was consumed in the process of fatigue crack initiation at $204{ }^{\circ} \mathrm{C}$. Conversely, most of the fatigue life at $704{ }^{\circ} \mathrm{C}$ was apparently taken up in propagation of fatigue cracks, initiated very early in life, at grain boundaries often attacked and weakened by corrosion in the pits (Fig. 3). This is consistent with the greater reductions in life observed for corroded specimens tested at $704{ }^{\circ} \mathrm{C}$.

The dimensions of pits initiating identifiable fatigue cracks were measured on the fracture surface of each specimen. Pit depth $(d)$ and width $(w)$ were measured for each initiation site as shown in Fig. 9, for approximately 3 to 15 initiation sites present on each fracture surface. Pits which caused fatigue
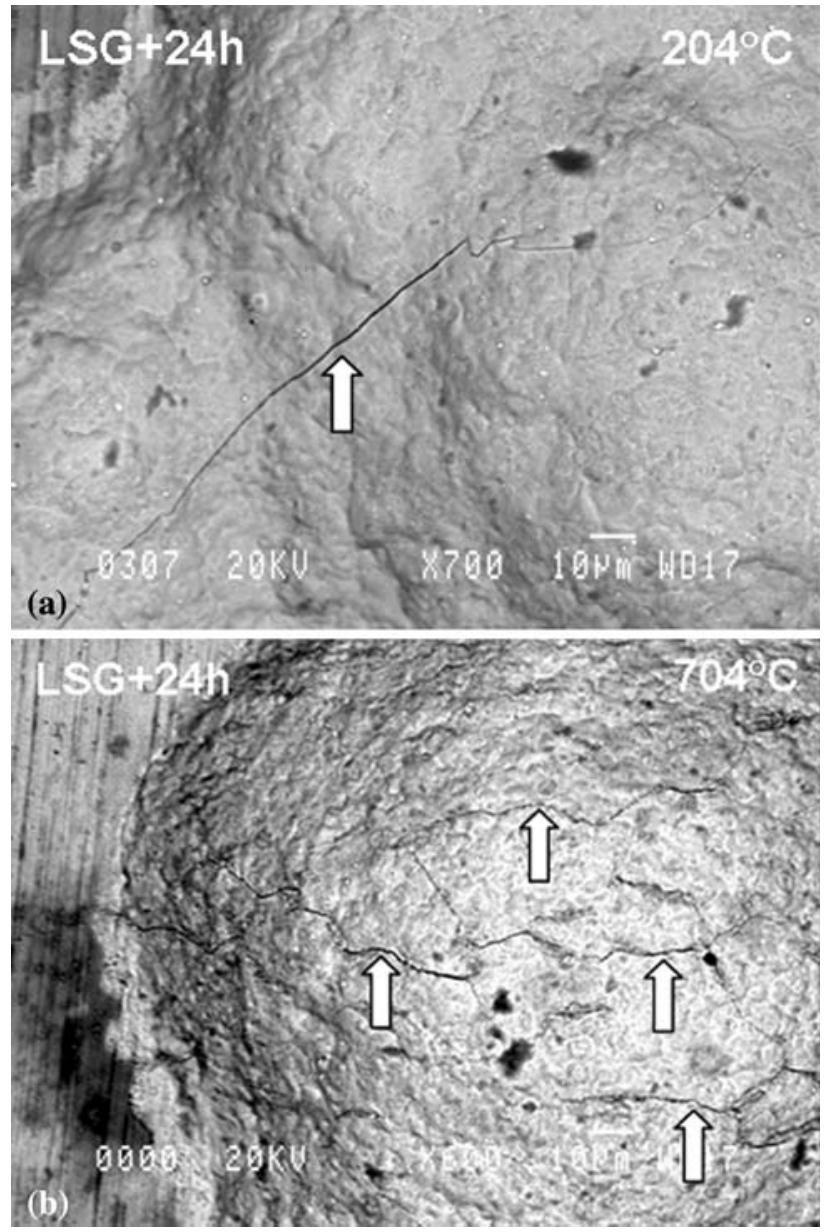

Fig. 11 Cracking at pits in interrupted test specimens with the loading direction oriented vertically, arrows indicating cracks: (a) $204{ }^{\circ} \mathrm{C}$, transgranular cracks observed at crystallographic facets for 33 to $55 \%$ of cyclic life and (b) $704{ }^{\circ} \mathrm{C}$, intergranular cracks for 5 to $10 \%$ of cyclic life

cracks had depths of 21 to $100 \mu \mathrm{m}$ and widths of $71 \mu \mathrm{m}$ to $4.56 \mathrm{~mm}$. The very large widths sometimes observed were due to the linking of some corrosion pits in the width direction along the edge of the melted salt ring, as evident in Fig. 2.

Fatigue damage often first initiates cracks at the largest defects. Therefore, the largest pit depth, width, and crosssectional area measured of the cracked pits on each fracture surface were first evaluated. Maximum pit dimensions were first compared versus corrosion time, as exemplified in the plot of maximum pit depth for specimens tested at 204 and $704{ }^{\circ} \mathrm{C}$ versus corrosion time in Fig. 12 and are summarized in Table 2. Maximum pit depth, width, and area all increased significantly with corrosion time. However, there was substantial overlap in values across time in most cases. These maximum pit dimensions are compared versus fatigue lives for each specimen in Fig. 13 and are summarized in Table 3. An increase of each pit dimension significantly decreased fatigue life. This is in agreement with previous work where fatigue life was related to pit depth (Ref 5, 7). The different pit dimensions were cross-correlated with specimen life, in that lower specimen life occurred in specimens having larger pit depth, width, and area. So, step-wise multiple linear regression could not be used to determine the best predictors and most influential 

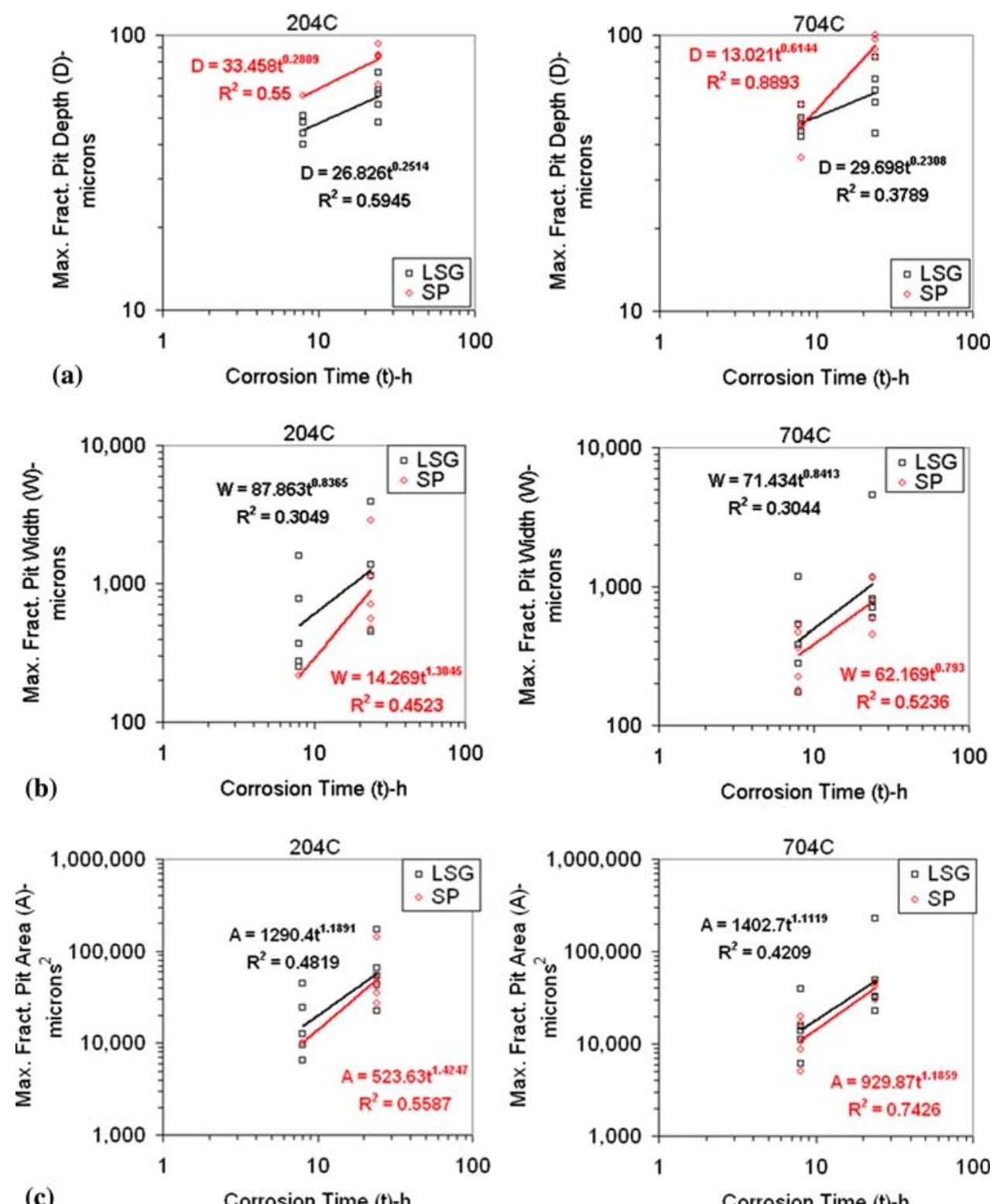

Fig. 12 Relationships between corrosion time and the maximum pit: (a) depth, (b) width, and (c) cross-sectional area on each corroded specimen's fracture surface

Table 2 Estimates of constants for corrosion time $(t)$ vs. maximum pit dimension $(P)$, using the equation $P=A t^{n}$

\begin{tabular}{|c|c|c|c|c|c|}
\hline $\begin{array}{l}\text { Machining } \\
\text { condition }\end{array}$ & $\begin{array}{c}\text { Test temperature, } \\
{ }^{\circ} \mathrm{C}\end{array}$ & $\begin{array}{c}\text { Max. Pit } \\
\text { dimension }\end{array}$ & Base, $A$ & Exponent, $n$ & $\begin{array}{c}\text { Coeff. of } \\
\text { determination, } \\
R^{2}\end{array}$ \\
\hline LSG & 204 & Depth & 26.826 & 0.2514 & 0.5945 \\
\hline $\mathrm{SP}$ & 204 & Depth & 33.458 & 0.2809 & 0.55 \\
\hline LSG & 704 & Depth & 29.698 & 0.2308 & 0.3789 \\
\hline $\mathrm{SP}$ & 704 & Depth & 13.021 & 0.6144 & 0.8893 \\
\hline LSG & 204 & Width & 87.863 & 0.8365 & 0.3049 \\
\hline $\mathrm{SP}$ & 204 & Width & 14.269 & 1.3045 & 0.4523 \\
\hline LSG & 704 & Width & 71.434 & 0.8413 & 0.3044 \\
\hline SP & 704 & Width & 62.169 & 0.793 & 0.5236 \\
\hline LSG & 204 & Area & 1290.4 & 1.1891 & 0.4819 \\
\hline SP & 204 & Area & 523.6 & 1.4247 & 0.5587 \\
\hline LSG & 704 & Area & 1402.7 & 1.1119 & 0.4209 \\
\hline $\mathrm{SP}$ & 704 & Area & 929.9 & 1.1859 & 0.7426 \\
\hline
\end{tabular}




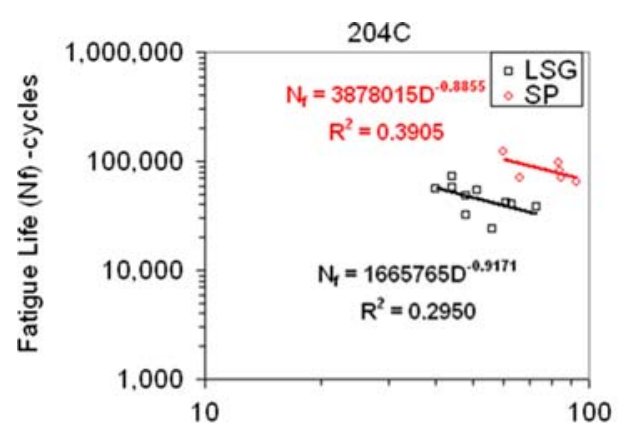

(a) Max. Fract. Pit Depth (D) -microns

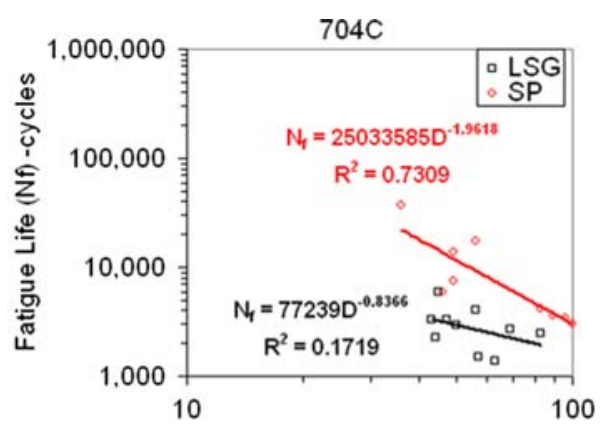

Max. Fract. Pit Depth (D) -microns
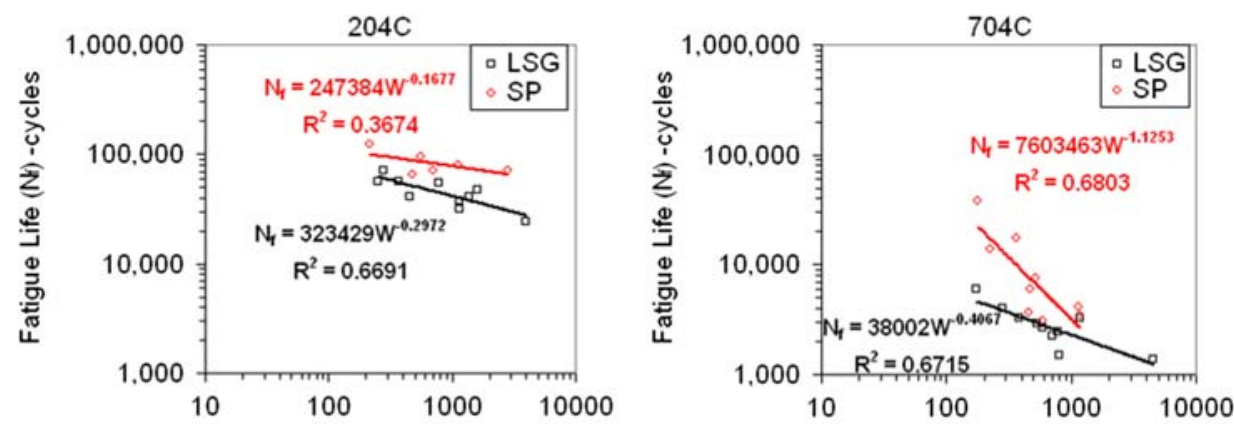

(b) Max. Fract. Pit Width $(W)$-microns

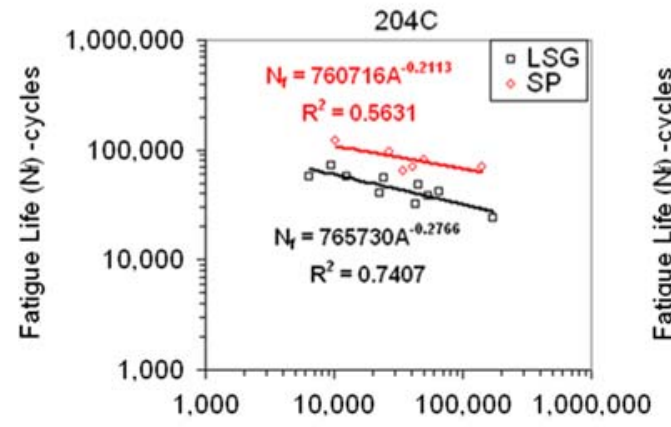

(c)

Max. Fract. Pit Area (A) -microns ${ }^{2}$

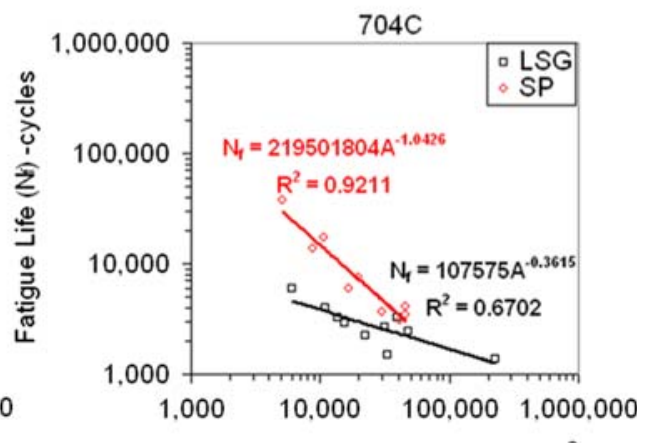

Max. Fract. Pit Area (A) -microns ${ }^{2}$

Fig. 13 Relationships between fatigue life and each corroded specimen's maximum pit: (a) depth, (b) width, and (c) cross-sectional area on its fracture surface

Table 3 Estimates of constants for maximum pit dimension $(P)$ vs. fatigue life $\left(N_{\mathrm{f}}\right)$, using the equation $N_{\mathrm{f}}=B P^{m}$

\begin{tabular}{lccrrr}
\hline Machining condition & Test temperature, ${ }^{\circ} \mathbf{C}$ & Max. Pit dimension & Base, $\boldsymbol{B}$ & Exponent, $\boldsymbol{m}$ & Coeff. of determination, $\boldsymbol{R}^{\mathbf{2}}$ \\
\hline LSG & 204 & Depth & $1,665,765$ & -0.9171 & 0.295 \\
SP & 204 & Depth & $3,878,015$ & -0.8855 & 0.3905 \\
LSG & 704 & Depth & 77,239 & -0.8366 & 0.1719 \\
SP & 704 & Depth & $25,033,585$ & -1.9618 & 0.7309 \\
LSG & 204 & Width & 323,429 & -0.2972 & 0.6691 \\
SP & 204 & Width & 247,384 & -0.1677 & 0.3674 \\
LSG & 704 & Width & 38,002 & -0.4067 & 0.6715 \\
SP & 704 & Width & $7,603,463$ & -1.1253 & 0.6803 \\
LSG & 204 & Area & 765,730 & -0.2766 & 0.7407 \\
SP & 204 & Area & 760,716 & -0.2113 & 0.5631 \\
LSG & Area & 107,575 & -0.3615 & 0.6702 \\
SP & 704 & Area & $219,501,804$ & -1.0456 & 0.9211 \\
\hline
\end{tabular}

dimensions. However, comparison of the coefficients of determination for each separately regressed dimension indicated pit cross-sectional area usually correlated with life better than either pit depth or width.
The above correlations of increasing fatigue life with decreasing pit size suggest a "critical" pit size could exist below which no fatigue cracks initiate to cause premature failure. Pits of a relatively wide range of sizes were intentionally 
Table 4 Estimates of critical pit dimensions required for fatigue cracking

\begin{tabular}{|c|c|c|c|c|c|c|c|c|c|}
\hline Condition & $\begin{array}{c}\text { Test } \\
\text { temperature, } \\
{ }^{\circ} \mathrm{C}\end{array}$ & $\begin{array}{c}\text { Pit } \\
\text { dimension }\end{array}$ & Count & $\begin{array}{l}\text { Min. } \\
\text { Exp. } \\
\text { Value }\end{array}$ & $\begin{array}{c}\text { Distribution } \\
\text { fit }\end{array}$ & $\begin{array}{l}\text { Adj. Coeff. of } \\
\text { determination, } \\
R^{2}\end{array}$ & $\begin{array}{c}\text { Est. } \\
p \text { value, } \\
\text { pve } \%\end{array}$ & $\begin{array}{c}\text { Dimension } \\
\text { at } p(.5) \text { prob. }\end{array}$ & $\begin{array}{c}\text { Critical } \\
\text { dimension } \\
\text { at } p(.001) \text { prob. }\end{array}$ \\
\hline $\mathrm{LSG}+8,24 \mathrm{~h}$ & 204 & Depth $(\mu \mathrm{m})$ & 81 & 22 & LogNormal & 0.987 & 50.83 & 41 & 19.6 \\
\hline $\mathrm{SP}+8,24 \mathrm{~h}$ & 204 & Depth $(\mu \mathrm{m})$ & 32 & 37 & LogNormal & 0.963 & 31.88 & 58 & 25.2 \\
\hline $\mathrm{LSG}+8,24 \mathrm{~h}$ & 704 & Depth $(\mu \mathrm{m})$ & 126 & 21 & LogNormal & 0.990 & 42.42 & 42 & 16.5 \\
\hline $\mathrm{SP}+8,24 \mathrm{~h}$ & 704 & Depth $(\mu \mathrm{m})$ & 57 & 30 & LogNormal & 0.972 & 19.63 & 61 & 23.8 \\
\hline $\mathrm{LSG}+8,24 \mathrm{~h}$ & 204 & Depth $(\mu \mathrm{m})$ & 81 & 22 & 3P Weibull & 0.982 & 16.03 & 42 & 19.1 \\
\hline $\mathrm{SP}+8,24 \mathrm{~h}$ & 204 & Depth $(\mu \mathrm{m})$ & 32 & 37 & 3P Weibull & 0.980 & 55.34 & 57 & 35.0 \\
\hline $\mathrm{LSG}+8,24 \mathrm{~h}$ & 704 & Depth $(\mu \mathrm{m})$ & 126 & 21 & 3P Weibull & 0.988 & 17.27 & 43 & 20.0 \\
\hline $\mathrm{SP}+8,24 \mathrm{~h}$ & 704 & Depth $(\mu \mathrm{m})$ & 57 & 30 & 3P Weibull & 0.973 & 8.29 & 62 & 27.1 \\
\hline $\mathrm{LSG}+8,24 \mathrm{~h}$ & 204 & Width $(\mu \mathrm{m})$ & 80 & 90 & LogNormal & 0.968 & 5.11 & 316 & 32.1 \\
\hline $\mathrm{SP}+8,24 \mathrm{~h}$ & 204 & Width $(\mu \mathrm{m})$ & 31 & 191 & LogNormal & 0.923 & 4.27 & 464 & 69.5 \\
\hline $\mathrm{LSG}+8,24 \mathrm{~h}$ & 704 & Width $(\mu \mathrm{m})$ & 125 & 71 & LogNormal & 0.960 & 0.412 & 302 & 40.1 \\
\hline $\mathrm{SP}+8,24 \mathrm{~h}$ & 704 & Width $(\mu \mathrm{m})$ & 56 & 102 & LogNormal & 0.973 & 22.49 & 384 & 83.9 \\
\hline $\mathrm{LSG}+8,24 \mathrm{~h}$ & 204 & Width $(\mu \mathrm{m})$ & 80 & 90 & 3P Weibull & 0.978 & 7.5 & 313 & 86.2 \\
\hline $\mathrm{SP}+8,24 \mathrm{~h}$ & 204 & Width $(\mu \mathrm{m})$ & 31 & 191 & 3P Weibull & 0.967 & 19.65 & 443 & 184.1 \\
\hline $\mathrm{LSG}+8,24 \mathrm{~h}$ & 704 & Width $(\mu \mathrm{m})$ & 125 & 71 & 3P Weibull & 0.964 & 0.216 & 313 & 67.1 \\
\hline $\mathrm{SP}+8,24 \mathrm{~h}$ & 704 & Width $(\mu \mathrm{m})$ & 56 & 102 & 3P Weibull & 0.973 & 8.69 & 405 & 78.6 \\
\hline $\mathrm{LSG}+8,24 \mathrm{~h}$ & 204 & Area $\left(\mu \mathrm{m}^{2}\right)$ & 80 & 1909 & LogNormal & 0.983 & 30.66 & 10,088 & 638 \\
\hline $\mathrm{SP}+8,24 \mathrm{~h}$ & 204 & Area $\left(\mu \mathrm{m}^{2}\right)$ & 31 & 6450 & LogNormal & 0.964 & 35.5 & 21,209 & 2398 \\
\hline $\mathrm{LSG}+8,24 \mathrm{~h}$ & 704 & Area $\left(\mu \mathrm{m}^{2}\right)$ & 125 & 1517 & LogNormal & 0.983 & 8.86 & 10,036 & 706 \\
\hline $\mathrm{SP}+8,24 \mathrm{~h}$ & 704 & Area $\left(\mu \mathrm{m}^{2}\right)$ & 56 & 2403 & LogNormal & 0.907 & 0.255 & 18,314 & 2350 \\
\hline $\mathrm{LSG}+8,24 \mathrm{~h}$ & 204 & Area $\left(\mu \mathrm{m}^{2}\right)$ & 80 & 1909 & 3P Weibull & 0.983 & 19.76 & 10,364 & 1849 \\
\hline $\mathrm{SP}+8,24 \mathrm{~h}$ & 204 & Area $\left(\mu \mathrm{m}^{2}\right)$ & 31 & 6450 & 3P Weibull & 0.976 & 40.86 & 21,075 & 5979 \\
\hline $\mathrm{LSG}+8,24 \mathrm{~h}$ & 704 & Area $\left(\mu \mathrm{m}^{2}\right)$ & 125 & 1517 & 3P Weibull & 0.978 & 2.14 & 10,175 & 1420 \\
\hline $\mathrm{SP}+8,24 \mathrm{~h}$ & 704 & Area $\left(\mu \mathrm{m}^{2}\right)$ & 56 & 2403 & 3P Weibull & 0.962 & 2.12 & 20,301 & 1097 \\
\hline
\end{tabular}

produced, and many were found to initiate fatigue cracks on the fracture surfaces. Therefore, cumulative probabilities for cracking at pits could be estimated versus ranked dimensions of all pits initiating cracks on the fracture surfaces of all specimens. Critical values of pit depth, width, and area having minimum $(p=0.001)$ probabilities of initiating fatigue cracks were thereby estimated, and are tabulated in Table 4. In this evaluation, both log normal and 3-parameter Weibull distribution assumptions were found to give good fits, Fig. 14.

Pit depth was found to give better correlations than other pit dimensions using both log normal and 3-parameter Weibull equations, Table 3 and Fig. 14. Coefficients of determination were well above 0.90 for all conditions using pit depth. Pit area had similar satisfactory correlations for fatigue specimens tested at $204{ }^{\circ} \mathrm{C}$, but somewhat lower values for those tested at $704{ }^{\circ} \mathrm{C}$. This appeared related to several outlier width and area values in each case. These high outlier values were from corrosion pits linked in the width direction along the edge of the melted salt mixture, as seen in Fig. 2. These joined pits perturbed the curve fits, but were nevertheless important based on their demonstrated influences on life, Fig. 13. They contributed to the curvature in the Weibull plots, which required fits using the 3-parameter curved Weibull equation rather than the 2-parameter straight Weibull equation, where the offset value $t_{\mathrm{o}}$ is held at zero. Pit width gave mixed intermediate results with high width values again producing curvature in both log normal and Weibull plots.

As summarized in Table 4, "critical" pit depths of 16 to $20 \mu \mathrm{m}$ were estimated to have a minimum probability of $p=0.001$ for initiating cracks in $\mathrm{LSG}+8,24 \mathrm{~h}$ specimens tested at 204 and $704{ }^{\circ} \mathrm{C}$. For SP $+8,24 \mathrm{~h}$ specimens, the estimated critical pit depth increased to $24-35 \mu \mathrm{m}$. Critical widths and areas also increased in the low-stress ground specimens compared to the shot-peened specimens at each test temperature. Selection of the log normal distribution assumption usually gave lower critical pit dimension estimates, which could be considered more conservative. However, the threeparameter Weibull fits often did a better job modeling curvature in the size distributions with more accurate capture of minimum experimental values. So, overall critical limits for pit depth, width, and area were estimated from the three-parameter Weibull fits, and are shown in Fig. 15 and 16. Overall critical values for pit depth of $18 \mu \mathrm{m}$, width of $63 \mu \mathrm{m}$, and crosssectional area of $800 \mu \mathrm{m}^{2}$ are suggested here with no benefits credited for shot peening. Note that these values are not exactly self-consistent, as a pit having an area of $800 \mu \mathrm{m}^{2}$ and depth of $18 \mu \mathrm{m}$ could have a width of no more than $57 \mu \mathrm{m}$ to avoid potential cracking. Conversely, a pit having an area of $800 \mu \mathrm{m}^{2}$ and width of $63 \mu \mathrm{m}$ could have a depth of no more than $16 \mu \mathrm{m}$ to avoid potential cracking. This lack of exact self-consistency can be attributed to residual errors in the regressions and their estimates of critical pit dimensions as well as elliptical approximations of pit shape.

In Fig. 16, plots of width versus depth are shown for all pits initiating cracks in all corroded specimens. These pits all had aspect ratios (depth/width) less than 0.5 , the value corresponding to a hemisphere. Smaller pits had aspect ratios approaching this value. This pit shape appeared to be an inherent characteristic of many pits that cracked. Some of the low observed pit aspect ratios were due to the joining of pits along the corrosion ring. Windows of pit depth and width dimensions estimated to have minimal potential for cracking are indicated. However, such estimates are preliminary and need to be updated as tests at other fatigue conditions are conducted and analyzed.

While maximum pit cross-sectional area correlated better with fatigue life than depth or width, a more important aspect may be the concentrated cyclic stresses and strains generated at 

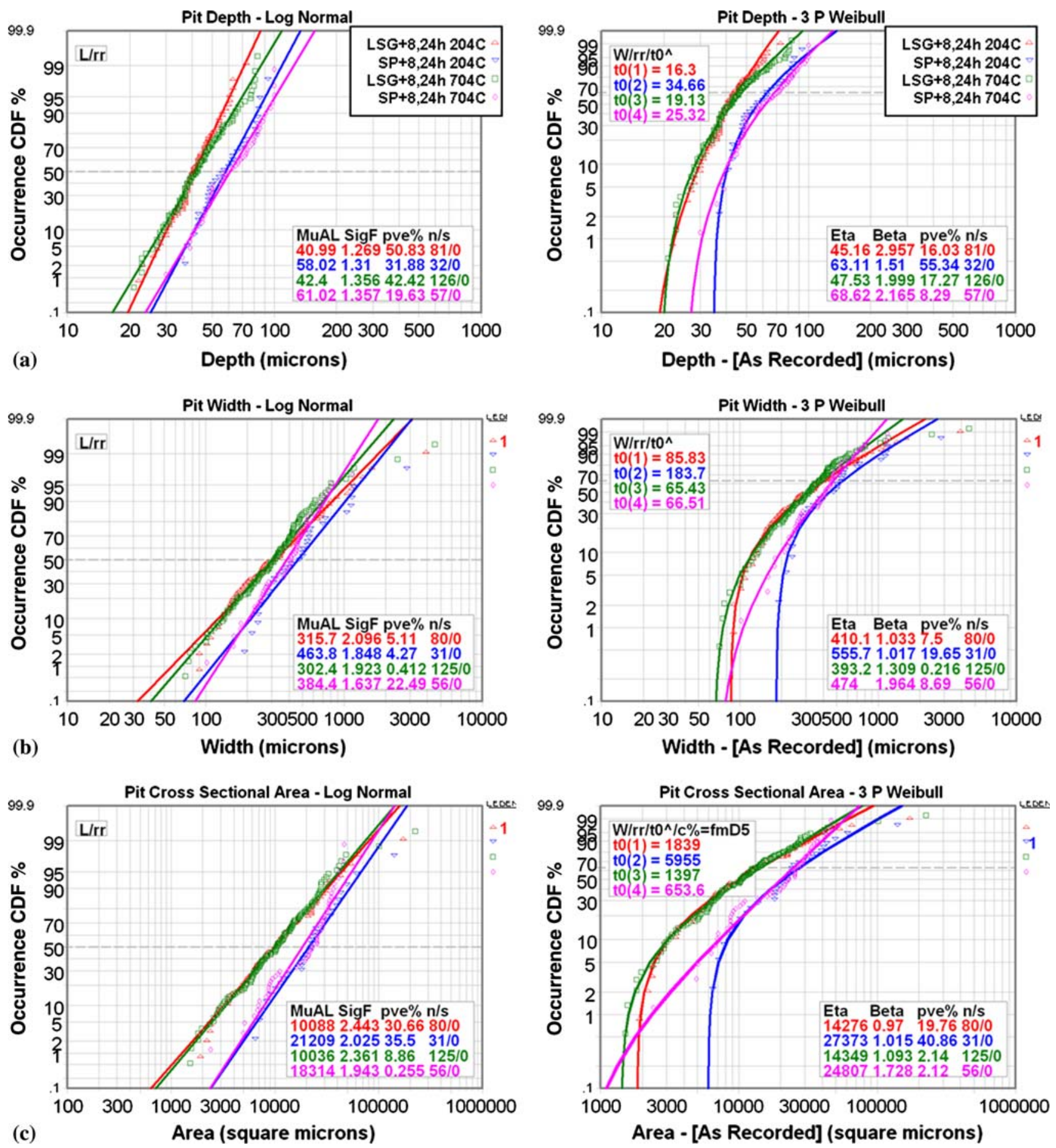

Fig. 14 Cumulative probability of cracking vs. pit: (a) depth, (b) width, and (c) cross-sectional area

each pit as functions of its dimensions and the test conditions. As a first step in this direction, a three-dimensional elastic finite element model was used to assess the effects of pit shape on stress concentration. The elastic stress concentration produced by a hemispherical pit with a depth/width aspect ratio of 0.5 was compared to that of a pit extended in one direction by $100 \%$, producing an ellipsoid having an aspect ratio of 0.25 . The single extended axis of the ellipsoid was oriented normal to the loading direction and parallel to the surface (NP), normal to the loading direction and normal to the surface $(\mathrm{NN})$, and parallel to the loading direction $(\mathrm{P})$. The elastic stress concentration of the hemispherical pit was estimated to be 2.0. For the ellipsoidal pit, the stress concentration was dependent on pit orientation. The $\mathrm{P}$ pit had a lower stress concentration of 1.4, while the NP and NN pits had higher stress concentrations of 2.5 to 2.6. These concentrated stresses would be limited by plastic flow at the pits when exceeding the yield stress, which is possible in the present fatigue tests. But 

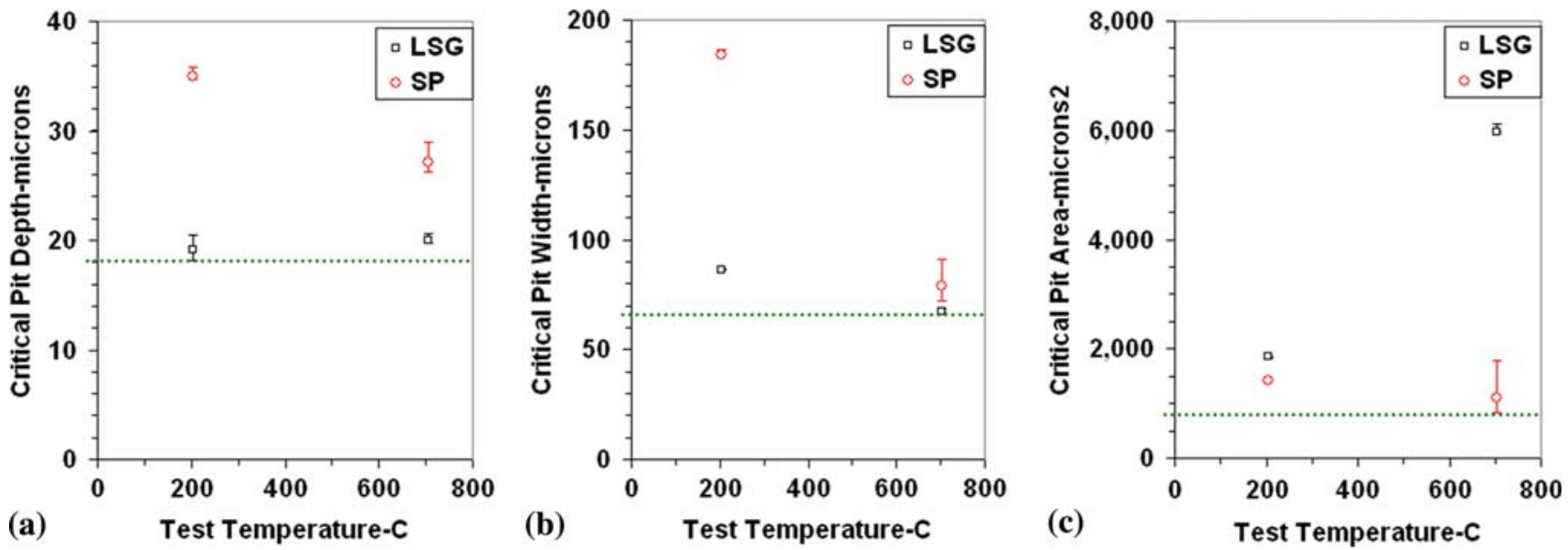

Fig. 15 Critical pit dimensions with their $95 \%$ confidence intervals estimated by three-parameter Weibull equations to have a minimum probability ( $p=0.001$ ) for cracking at the chosen fatigue test conditions: (a) depth, (b) width, and (c) cross-sectional area
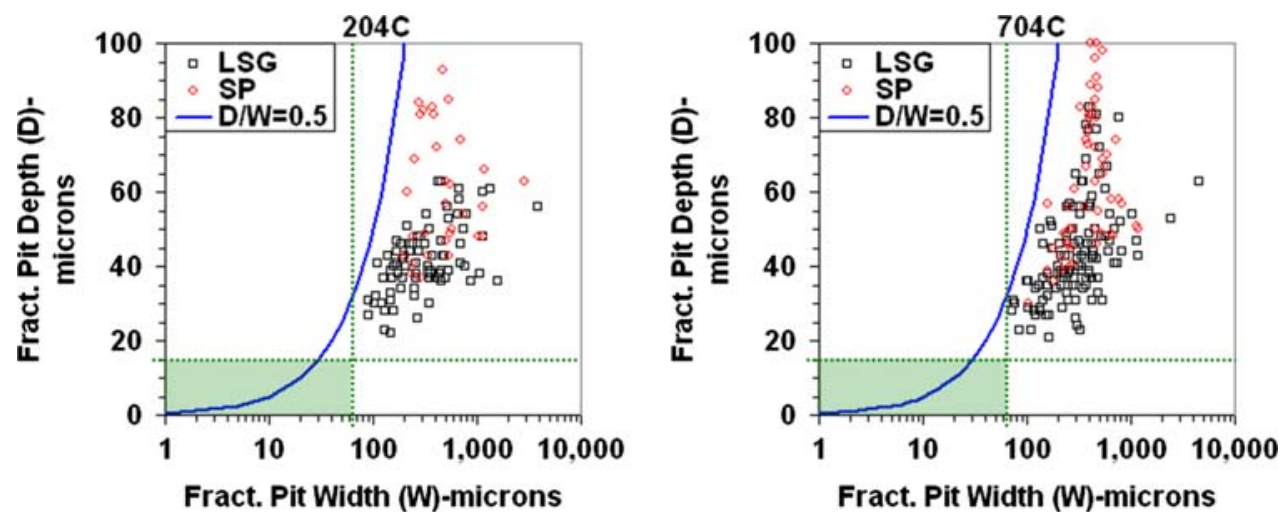

Fig. 16 Depth vs. width of all pits initiating fatigue cracks on each specimen's fracture surface, with shaded region indicating where pits have minimal probability of initiating fatigue cracks for the current test conditions

this would result in more plastic deformation and consumption of ductility for pits having higher elastic stress concentrations. Overall, the elastic model results do signify that pit morphology and orientation do influence the concentrated stresses and strains generated at a pit, and that extended, wide pits could have higher stresses and resulting propensity for cracking than hemispherical pits at a constant depth, supporting the results in Fig. 16.

Note that the finite element modeling of small pits on the surface of large cross sections did not indicate a strong dependence of stress concentration on pit depth. However, the stress intensities of surface cracks having profiles similar to these pits are well known to increase with depth (Ref 18). The strong relationships of probability for cracking with pit depth in Fig. 14 indicate this depth dependence for crack propagation is also an important consideration operative here. However, in the present case, a surface crack at a pit would be growing through the concentrated stress field generated by the pit.

Further analyses of the concentrated stresses and strains at pits are still required. These parameters drive crack initiation at pits, and then influence stress intensity along a pit front which drive crack propagation, determining total fatigue cycles to specimen failure. This would also allow considerations of actual cyclic stress range and maximum stress generated during each fatigue test. While the tests were performed at a constant cyclic strain range and strain ratio for each temperature, stress range and maximum stress slightly varied in each test specimen. This could be attributed to differences in specimen mechanical response rooted in varying microstructure (Fig. 1), due to varying prior location of specimens from within disks given different solution heat treatment quenches (Ref 13). The effects of cyclic stress variations on observed fatigue life were analyzed and found to be insignificant in most cases. Nevertheless, estimation of concentrated stresses and strains at pits with inclusion of these effects would help identify critical pit stress parameters, refine the estimated critical pit dimensions, and allow their extension to other, untested fatigue conditions.

Further analyses of the concentrated stresses and strains at pits could also help support application of surface enhancement processes including conventional shot peening, laser shock peening, and low plasticity burnishing to better suppress fatigue cracking at pits. The effects of temperature and time exposures during service on their generated compressive residual stresses and cold work could then be screened. But the effects of the eventual magnitudes and depths of compressive residual stresses and cold work on the local concentrated stresses and strains at pits might be more important determinants of fatigue cracking there, and could be considered. 


\section{Summary of Results}

The effects of hot corrosion pits on low-cycle fatigue life and failure modes of powder metallurgy disk superalloy ME3 were examined. Low-cycle fatigue specimens were machined from several disks, in some cases shot peened, and subjected to accelerated hot corrosion exposures to produce corrosion pits. The specimens were then tested at 204 and $704{ }^{\circ} \mathrm{C}$ in low-cycle fatigue. Fatigue lives and failure initiation mechanisms were compared to those of specimens without corrosion exposures.

Prior corrosion exposures produced pits that reduced fatigue life 60 to $98 \%$ by encouraging early preferential fatigue cracking at these pits. Shot peening mitigated effects of light corrosion for fatigue tests at $204{ }^{\circ} \mathrm{C}$, but not of heavy corrosion on fatigue life at either test temperature. Critical pit sizes were estimated based on measurements of all pits initiating cracks on fracture surfaces.

\section{Conclusions}

Hot corrosion pitting can occur for disk superalloys having salt deposits and exposures near $704^{\circ} \mathrm{C}$. These pits can significantly reduce low-cycle fatigue life at low and high temperatures. Shot peening can induce near-surface compressive residual stresses which appear able in some cases to mitigate the effects of corrosion pits on fatigue life. However, both longer corrosion time and fatigue at high temperatures can still produce large reductions in fatigue life for shot-peened specimens due to fatigue cracking at corrosion pits. Increasing pit dimensions significantly influence the probability for fatigue crack initiation and resulting fatigue lives for the test conditions evaluated. Critical pit dimensions can therefore be estimated for fatigue cracking at pits in these test conditions.

Further work is necessary to better understand the effects of hot corrosion pits on fatigue life. Fatigue tests need to be performed at other strain conditions and temperatures to determine critical pit values as functions of these variables. Additional interrupted tests are needed to further quantify and separate crack initiation and propagation processes. Further modeling will be needed of the stress and strain concentrations produced by various pit morphologies to determine if local critical stress and strain conditions are required for fatigue crack initiation there. Modeling of the crack driving force along the complex geometries of pit fronts will be needed to see if a threshold exists for crack growth and to determine crack growth rate curves. Additional corrosion exposures for shorter times would be helpful to generate even smaller, more widely separated pits for determination of their influences on fatigue crack initiation and growth. Subsequently, carefully varied fatigue tests of variously corroded specimens could be used to independently verify the critical pit considerations described above.

Optimized surface enhancement processes such as shot peening, laser shock peening, and low plasticity burnishing may still have some potential to produce sufficient, stable compressive residual stresses to suppress fatigue cracking at corrosion pits. However, environmental barrier coatings may ultimately be needed in some cases to prevent pit formation by isolating any corrosive salts from superalloy surfaces.

\section{Acknowledgments}

The authors would like to acknowledge Ron Tolbert at GE Aviation for technical work, John Gayda at NASA Glenn Research Center for finite element modeling, James W. Smith for microprobe evaluations, and the NASA Aviation Safety and Intelligent Propulsion programs for support.

\section{References}

1. R. Schafrick and R. Sprague, Saga of Gas Turbine Materials, Part IV, Adv. Mater. Process., 2004, 162(66), p 41-46

2. R.A. Rapp, Hot Corrosion of Materials: A Fluxing Mechanism?, Corros. Sci., 2002, 44, p 209-221

3. F.S. Pettit and C.S. Giggins, Hot Corrosion, Superalloys II, C.T. Sims, N.S. Stoloff, and W.C. Hagel, Eds., John Wiley \& Sons, New York, 1987, p 327-358

4. J.L. Smialek, C.A. Barrett, and J.C. Schaeffer, Design for Oxidation Resistance, ASM Handbook V. 20, Materials Selection and Design, American Society for Metals, Metals Park, OH, 1990, p 589-602

5. J.R. Groh and R.W. Duvelius, Influence of Corrosion Pitting on Alloy 718 Fatigue Capability, Superalloy 718, 625, 706 and Derivatives, E.A. Loria, Ed., The Mining, Metallurgy, and Materials Society, Warrendale, PA, 2001, p 583-592

6. A. Encinas-Oropesa, G. Drew, M. Hardy, A. Leggett, J. Nicholls, and N. Simms, Effects of Oxidation and Hot Corrosion in a Nickel Disc Alloy, Superalloys 2008, R.C. Reed, K.A. Green, P. Caron, T.P. Gabb, M.G. Fahrmann, E.S. Huron, and S.A. Woodard, Eds., The Mining, Metallurgy, and Materials Society, Warrendale, PA, 2008, p 609-618

7. S.I. Rokhlin, J.-Y. Kim, H. Nagy, and B. Zoofan, Effect of Pitting Corrosion on Fatigue Crack Initiation and Fatigue Life, Eng. Fract. Mech., 1999, 62, p 425-444

8. S. Kawai and K. Kasai, Considerations of Allowable Stress of Corrosion Fatigue (Focused on the Influence of Pitting), Fat. Fract. Eng. Struct., 1985, 8(2), p 115-127

9. P. Shi and S. Mahadevan, Damage Tolerance Approach for Probabilistic Pitting Corrosion Fatigue Life Prediction, Eng. Fract. Mech., 2001, 68, p 1493-1507

10. D.P. Mourer and J.L. Williams, Dual Heat Treat Process Development for Advanced Disk Applications, Superalloys 2004, K.A. Green, T.M. Pollock, H. Harada, T.E. Howson, R.C. Reed, J.J. Schirra, and S. Walston, Eds., The Mining, Metallurgy, and Materials Society, Warrendale, PA, 2004, p 401-408

11. J.R. Groh and D.P. Mourer, Alternate Material for Elevated Temperature Turbine Cooling Plate Applications, Superalloys 2004, K.A. Green, T.M. Pollock, H. Harada, T.E. Howson, R.C. Reed, J.J. Schirra, and S. Walston, Eds., The Mining, Metallurgy, and Materials Society, Warrendale, PA, 2004, p 101-108

12. T.P. Gabb, J. Telesman, P.T. Kantzos, and K. O'Connor, "Characterization of the Temperature Capabilities of Advanced Disk Alloy ME3," NASA/TM-2002-211796, National Aeronautics and Space Administration, Washington, DC, August 2002

13. T.P. Gabb, A. Garg, D.L. Ellis, and K.M. O'Connor, "Detailed Micro Characterization of the Disk Alloy ME3," NASA/TM-2004-213066, National Aeronautics and Space Administration, Washington, DC, May 2004

14. W. Weibull, A Statistical Distribution Function of Wide Applicability, ASME J. Appl. Mech., 1951, 18, p 293-297

15. R.B. Abernethy, The New Weibull Handbook, 5th ed., Robert B. Abernethy, North Palm Beach, FL, 2006

16. P.S. Prevey, X-Ray Diffraction Residual Techniques, Metals Handbook, 9th ed., American Society for Metals, Metals Park, OH, 1986, 10, p 380-392

17. T.P. Gabb, J. Telesman, P.T. Kantzos, and A. Garg, Effects of Temperature on Failure Modes for a Nickel-Base Disk Superalloy, J. Fail. Anal. Prev., 2007, 7(1), p 56-65

18. R.H. Vanstone and T.L. Richardson, "Potential-Drop Monitoring of Cracks in Surface-Flawed Specimens," ASTM STP 977, American Society for Testing and Materials, West Conshohocken, PA, 1985, p 148-166 